\title{
Squamous Cell Carcinoma from Abscessed, Mature Cystic Ovarian Teratoma - A Case Report and Literature Review
}

\author{
NICOLAE BACALBASA ${ }^{1,2,3}$, DRAGOS CRETOIU ${ }^{1,4}$, IOANA HALMACIU $^{5}$, \\ CAMELIA DIACONU ${ }^{1,6}$, LAURA ILIESCU $^{1,7}$, SIMONA DIMA ${ }^{3}$, ADRIAN NEACSU ${ }^{1,8}$, \\ CRISTIAN BALALAU ${ }^{1,9}$, OVIDIU GABRIEL BRATU ${ }^{1,10}$ and IRINA BALESCU ${ }^{11}$ \\ 1 "Carol Davila" University of Medicine and Pharmacy, Bucharest, Romania; \\ ${ }^{2}$ Department of Obstetrics and Gynecology, "I. Cantacuzino" Clinical Hospital, Bucharest, Romania; \\ ${ }^{3}$ Department of Visceral Surgery, Center of Excellence in Translational \\ Medicine "Fundeni" Clinical Institute, Bucharest, Romania; \\ 4"Alessandrescu-Rusescu" National Institute of Mother and Child Health, \\ Fetal Medicine Excellence Research Center, Bucharest, Romania; \\ ${ }^{5}$ Department of Anatomy, "George Emil Palade" University of Medicine, \\ Pharmacy, Science and Technology, Târgu Mureș, Romania; \\ ${ }^{6}$ Department of Internal Medicine, University Emergency Hospital Bucharest, Bucharest, Romania; \\ ${ }^{7}$ Department of Internal Medicine, "Fundeni" Clinical Institute, Bucharest, Romania; \\ ${ }^{8}$ Department of Obstetrics and Gynecology, "St. John” Emergency Clinical Hospital, Bucharest, Romania; \\ ${ }^{9}$ Department of Surgery, "Pantelimon" Clinical Hospital, Bucharest, Romania; \\ ${ }^{10}$ Department of Urology, Emergency Central Military Hospital, \\ Academy of Romanian Scientists, Bucharest, Romania; \\ ${ }^{11}$ Department of Surgery, "Ponderas" Academic Hospital, Bucharest, Romania
}

\begin{abstract}
Background/Aim: Malignant transformation of mature cystic ovarian teratoma is a scarce eventuality, only rare cases being reported so far. Furthermore, development of this transformation in the setting of an abscessed tumor is even scarcer. The aim of this study was to report the case of a 47-year-old patient submitted to surgery for such a lesion. Case Report: The patient was investigated for diffuse pelvic pain and diagnosed with a $10 \times 7 \times 8 \mathrm{~cm}$ mass at the level of the left adnexa with imaging findings suggesting the presence of an ovarian teratoma. The patient was submitted to surgery involving a total hysterectomy with bilateral adnexectomy, lymphadenectomy and peritoneal biopsies. The histopathological examination demonstrated the presence of squamous cell carcinoma areas transformation in association with areas of abscess. Postoperatively the patient was
\end{abstract}

This article is freely accessible online.

Correspondence to: Nicolae Bacalbasa, "I. Cantacuzino" Clinical Hospital, 5-7, Ion Movilă Street, Bucharest, Romania. Tel: +40 723540426,e-mail: nicolae_bacalbasa@yahoo.ro

Key Words: Squamous cell carcinoma, abscess, mature ovarian teratoma. submitted to six cycles of platinum-based chemotherapy and concurrent external radiotherapy. At one-year follow-up she is free of recurrent disease. Conclusion: Although malignisation of mature cystic ovarian teratoma is a rare event, it should not be omitted when mature ovarian teratoma is suspected; however, association between malignant transformation and abscess is a scarcer eventuality.

Although mature cystic teratoma accounts for $20 \%$ of all ovarian tumors, malignisation of these tumors occurs in less than $2 \%$ of cases; the vast majority of cases will exhibit transformation into squamous cell carcinomas (1). However, it seems that malignant transformation usually occurs in elderly patients, the age of such cases ranging from 45 to 60 years (1). As for the clinical signs and symptoms, they are strongly related to the clinical stage and extension of the disease; while cases diagnosed in early stages might develop non-specific symptoms such as diffuse pelvic pain, in more advanced stages abdominal distension due to the presence of multiple tumoral masses, visceral compression or invasion might appear. Therefore, these patients will exhibit different signs induced by bowel, colon or urinary bladder dysfunctions (2). Due to the non-specific signs and symptoms reported especially in cases diagnosed in early stages of the disease, in a significant number of cases a 
positive diagnosis will be suggested intraoperatively by the frozen section and demonstrated later by histopathological examination. Regarding the management of these tumors, due to the rarity of cases, no standard therapeutic protocol has been proposed so far, experience being limited to case reports or case series (2).

\section{Case Report}

A 47-year-old postmenopausal patient, with no significant family history of neoplastic diseases and with no significant medical history, self-presented for diffuse pelvic pain. The abdominal ultrasound raised the suspicion of a left adnexal mass.

The patient was further submitted to a gynecological examination and to a transvaginal ultrasound, which confirmed the presence of a left adnexal mass measuring $10 \times 7 \times 8 \mathrm{~cm}$; the mass proved to have cystic features in association with intracystic fat, raising the suspicion of an ovarian teratoma. In addition, areas of acoustic shadowing were discovered, raising the suspicion of a Rokitansky nodule exhibiting solid components such as hair and teeth. The imaging studies were further completed by performing a pelvic magnetic resonance imaging which demonstrated the presence of irregular soft tissue areas at the level of the ovarian cyst. The laboratory tests revealed normal serum levels of cancer antigen 125 (CA125), carcinoembryonic antigen and squamous cell carcinoma antigen. A total hysterectomy with bilateral adnexectomy was performed, and a specimen was submitted to frozen section. At this moment, areas of squamous cell carcinoma were demonstrated in association with areas of infection suggestive of the presence of an intracystic abscess. Due to the presence of malignant elements, the surgical procedure was completed by performing pelvic and para-aortic lymph node dissection, serial peritoneal biopsies, omentectomy and peritoneal washing. The paraffin examination confirmed the presence of malignant transformation in association with areas of abscess within the ovarian tumor. The omentectomy, peritoneal biopsies as well as the peritoneal washing demonstrated the absence of tumoral masses (Figures 1 and 2). The postoperative course was uneventful; the patient was discharged in the fifth postoperative day and further confined to the oncology clinic where she was submitted to six cycles of platinum-based chemotherapy in association with whole pelvis radiotherapy. At one-year follow-up the patient is free of any recurrent disease.

\section{Discussion}

Initially described 300 years ago, these tumors were considered to be small babies, one of the greatest concerns being represented by the necessity of baptizing them (3). However, histopathological studies demonstrated that in fact these lesions are ovarian tumors originating from the primordial germ cells (4).

Ovarian teratoma develops from germ cells and might present different cellular types originating from one or more of the germ layers, represented by endoderm, ectoderm and mesoderm $(4,5)$. Therefore, various structures might be encountered at the level of the ovarian lesions such as epidermis, sebaceous or sweat glands from the ectodermal structures, teeth, muscle, fat or bone - originating from the mesodermal structures or even gastrointestinal, respiratory or even thyroid tissues originating from the endodermal structures $(4,6)$. The lesion might induce the development of common signs and symptoms such as abdominal pain, urinary or digestive symptoms or it might remain asymptomatic until the moment in which complications occur; as for the most frequently encountered complications, they are represented by torsion, intraperitoneal rupture or even invasion of the adjacent viscera (7). When it comes to malignant transformation and infection, these complications have been rarely reported, the estimated incidence being 1$2 \%$ of all reported cases (2).

Malignant transformation of ovarian teratoma can arise from any type of germ cell that is present at the level of these tumors; therefore, adenocarcinomas, squamous cell carcinomas, sarcomas, melanomas, adenosquamous carcinomas or even carcinoid tumors might occur. However, it seems that up to $80 \%$ of cases exhibiting malignant features prove to be squamous cell carcinomas $(8,9)$.

In order to provide a better preoperative identification of cases in which malignant transformation might have occurred, multiple criteria have been proposed; therefore, elderly patients (usually after 55 years of age), presenting larger tumors (defined as larger than $10 \mathrm{~cm}$ ) and radiological signs of intra-tumoral vascularization seem to be more likely to present malignant transformation of ovarian teratomas. Furthermore, due to the fact that most often these tumors exhibit squamous cell carcinoma transformation, certain authors investigated the sensibility and specificity of squamous cell carcinoma antigen for identifying cases at risk; however, this criterion is still under debate, and the cut off value has not yet been established (10-13). When it comes to the age at which this lesion might be encountered, it has been demonstrated that these patients are 10-15 years older when compared to cases diagnosed with benign lesions (14).

As for the type of surgical approach which should be taken in consideration, it seems that the open approach should be the option of choice. Although the minimally invasive route seems attractive in such situations due to a better recovery of the patient, certain authors have underlined the fact that this procedure should be avoided due to the high risk of spillage and cystic effraction during laparoscopic manipulation and extraction of the specimen $(15,16)$. However, if laparoscopic approach is the option of 


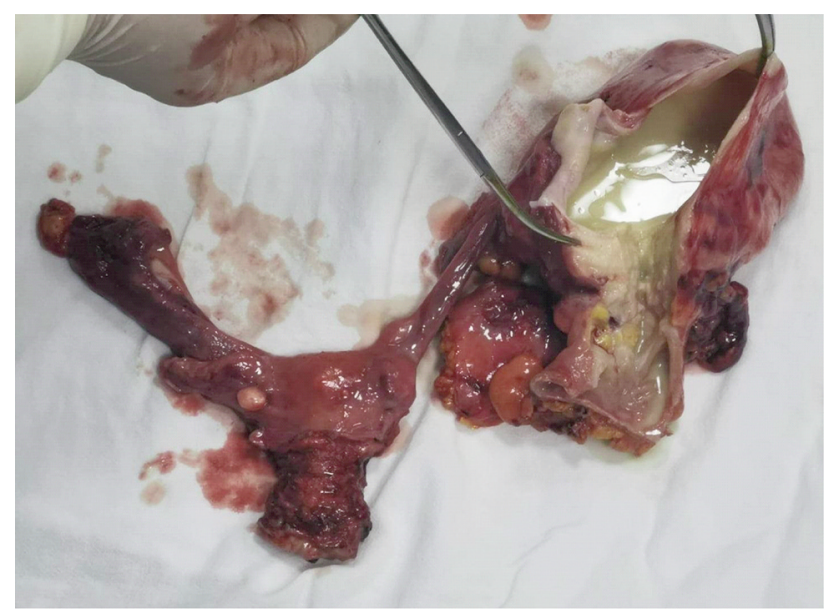

Figure 1. The specimen of total hysterectomy with bilateral adnexectomy presenting an abscessed left ovarian tumor, which proved to be a mature teratoma with areas of squamous cell carcinoma.

choice and spillage occurs, adequate peritoneal washing with warmed fluids in strongly recommended in order to prevent the development of further peritoneal lesions (17). Moreover, more recent studies have come to demonstrate that the minimally invasive surgical procedure might be safely performed if the specimen is placed in an endoscopic bag of retrieval (18).

As for the extent of the surgical procedure, while most authors consider that serial peritoneal biopsies should be performed in order to achieve a proper staging of the disease, when it comes to the effectiveness of lymph node dissection, this procedure is not widely accepted due to the fact that the lymphatic route is not considered to be a preferential one for this type of tumors (19-21). However, when it comes to the role of debulking surgery, the effectiveness of complete cytoreductive surgery is unanimously accepted. Other prognostic factors which seem to strongly influence the longterm outcomes in such cases, are represented by the stage at the time of diagnosis, intraperitoneal rupture of the tumor, vascular invasion and pattern of growth $(2,8)$. Certain authors went even further and tried to demonstrate that the age at diagnosis, the serum levels of the tumor markers or the degree of tumoral differentiation might also impact the long-term outcomes; however, these data are scarce, and no significant correlation has been observed so far $(22,23)$.

Unfortunately, it is estimated that squamous cell carcinoma originating from malignant ovarian teratoma is associated with the poorest prognosis, the five-year overall survival being even scarcer than in cases diagnosed with epithelial ovarian cancer $(6,24-29)$.

In cases in which fertility preservation is desired, salpingo-oophorectomy might be proposed, especially in

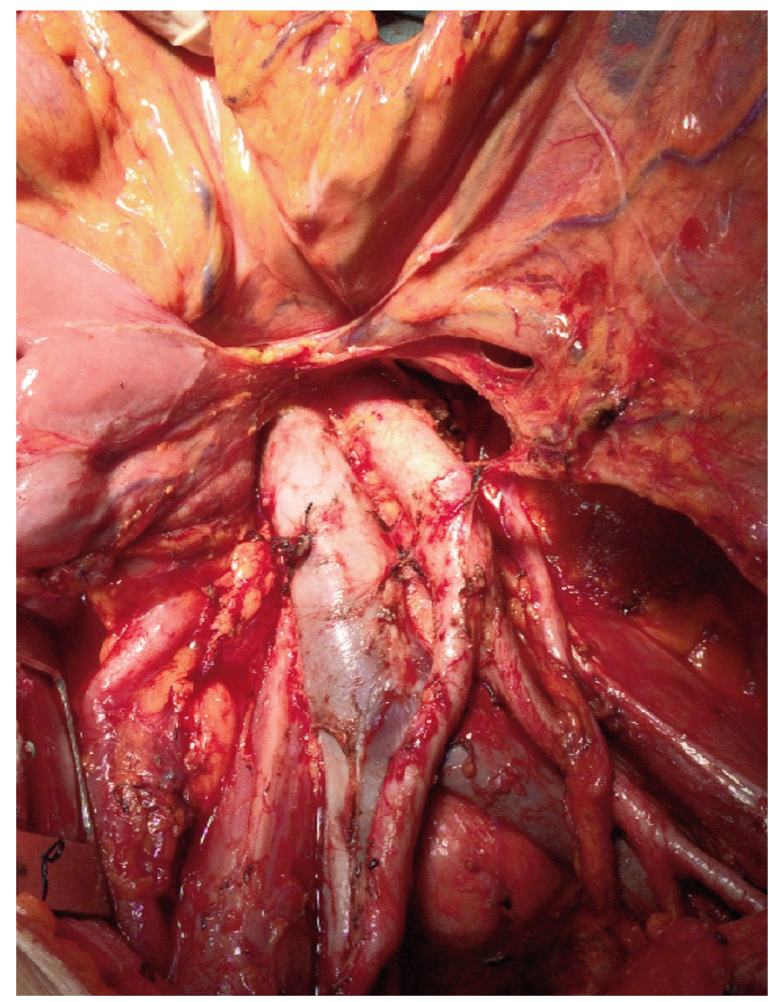

Figure 2. The final aspect after total hysterectomy with bilateral adnexectomy, pelvic and para-aortic lymph node dissection.

patients diagnosed in apparently early stages of the disease. However, attentive follow-up is mandatory in such cases in order to identify properly cases in which disease progression occurs $(22,30)$.

Once the diagnosis and staging is completely performed, the patient will be submitted to postoperative follow-up or will be confined to the oncology department in order to be submitted to adjuvant treatment (30). Although cases diagnosed in apparently early stages with characteristics demonstrating a favorable tumoral biology might be submitted only to a follow-up protocol, in certain patients, recurrent disease might develop. In the study by Chen $\mathrm{P}$ et al., the authors reported the case of a 55-year-old postmenopausal woman, which was diagnosed with a $5 \mathrm{~cm}$ ovarian mass who was submitted to total abdominal hysterectomy with bilateral adnexectomy (31). The histopathological findings demonstrated the presence of a malignant teratoma with areas of squamous cell carcinoma; therefore, the surgical procedure was considered to be a complete one, while the patient had no other gravity signs small dimension of the tumor, the absence of significant laboratory test modifications. In this respect, the patient was not considered to be candidate for adjuvant therapy; however, two months later she self-presented for diffuse 
pelvic pain and was diagnosed with a $20 \mathrm{~cm}$ tumoral mass located at the level of the pelvic area, invading the sigmoidian loop. Debulking surgery followed by adjuvant chemotherapy was performed, and the patient was free of disease at the three-year follow-up (31).

As for the most appropriate type of adjuvant treatment, it seems that the association between platinum-based therapy and whole pelvis radiation therapy is beneficial in most of the cases due to the particular histopathological aspect of these lesions; the high amount of squamous cell carcinoma features of these tumors led to the conclusion that these types of malignancies should be rather treated as cervical or vulvar cancers (which exhibit a similar cellularity) than of ovarian cancers (which are usually adenocarcinomas) (2). One of the largest review studies conducted on the issue of squamous cell carcinoma degeneration of mature cystic ovarian teratoma included 17 cases, which were identified over a period of 22 years; the mean age at the time of diagnosis was 55 years, most cases being diagnosed in early stages of the disease. The authors underlined the fact that none of the cases submitted to lymph node dissection exhibited lymphatic metastases. As for the long-term outcomes, the same study group demonstrated the fact that the overall one year survival rate was $60 \%$, and was significantly influenced by the stage at the time of diagnosis and by the type of the adjuvant therapy. Therefore, cases diagnosed in stage I of disease and submitted to adjuvant platinum-based chemotherapy and pelvic irradiation reported the best longterm outcomes (2).

One of the largest single institutional studies conducted on this topic originates from Korea and was published by Park JY in 2008 (32). The study included all patients diagnosed with ovarian malignancies between 1989 and 2007 at the Asan Medical Center, Korea. The authors underlined the fact that there were 16 patients diagnosed with malignant transformation of ovarian teratomas, and the rate of malignant transformation was $0.8 \%$. Moreover, the authors reported that these cases accounted for $1.7 \%$ of all ovarian cancers, the mean age at the time of the diagnosis was 50 years, and the mean tumoral diameter was $14.5 \mathrm{~cm}$. As for the therapeutic strategy, it seems that staging surgery in presumptive early stages of the disease, as well as debulking surgery for more advanced stages represented the best therapeutic option. However, the completeness of cytoreduction was also reinforced with the use of adjuvant chemotherapy or chemo-radiotherapy in order to achieve a better control of the disease; the mean number of administrated cycles of chemotherapy was 4 . After a median follow-up of 23 months, three patients reported progressive disease, while other four patients developed recurrent disease, the 5 -year overall survival rate being $51 \%$. The univariate analysis demonstrated that the initial stage at diagnosis as well as the administration of adjuvant chemotherapy or chemo-irradiation seems to influence the most the overall prognosis of these patients (32).

In 2008, one of the largest systematic reviews was published on the issue of squamous cell carcinoma transformation of mature ovarian teratomas and included papers published between 1978 and 2007 (4). The authors included 64 such studies summarizing 277 patients. The mean age at the time of diagnosis was 55 years, and patients were mostly diagnosed in early stages of the disease. No significant correlation could be established between the serum levels of tumor markers and the stage at diagnosis; however, patients diagnosed in advanced stages had a significantly poorer outcome. Interestingly, patients diagnosed in early stages but presenting ruptured tumors did not experience a poorer outcome. When it comes to the role of the adjuvant therapy, the authors underlined the fact that only the administration of alkylating agents might improve the survival, while the role of radiation therapy was considered rather a doubtable one (4).

As for the case we here report, the most important particularity which should be underlined is the fact that the ovarian tumor associated both malignant transformation and an ovarian abscess; the literature data came to demonstrate that while $2 \%$ of cases might develop malignisation, only $1 \%$ of this histopathological subtype present as infected lesions at the time of diagnosis $(12,33)$.

\section{Conclusion}

Although ovarian teratomas are frequently encountered, a small proportion of them will develop further complications, such as infection or malignisation. Moreover, association of the two complications - infection and malignisation represents a scarcer event. In cases in which malignant transformation occurs, squamous cell carcinoma is the most commonly encountered type of malignancy. In such cases radical surgery with curative intent, followed in most cases by adjuvant chemotherapy and in certain cases by chemoirradiation, represents one of the most efficient therapeutic strategies. However, attention should be paid to the followup protocol of such cases, as an important number of cases develop recurrent disease.

\section{Conflicts of Interest}

The Authors have no conflicts of interest to declare regarding this study.

\section{Authors' Contributions}

$\mathrm{NB}$, OGB, AN performed the surgical procedure; IH reviewed literature data, $\mathrm{CD}, \mathrm{LI}, \mathrm{SD}$ preoperative investigation the patient, IB, CB prepared the draft of the manuscript, IB was advisor of the surgical oncology procedures. DC was advisor of the oncological outcome. All Authors read and approved the final version of the manuscript. 


\section{Acknowledgements}

This work was supported by the project entitled "Multidisciplinary Consortium for Supporting the Research Skills in Diagnosing, Treating and Identifying Predictive Factors of Malignant Gynecologic Disorders", project number PN-III-P1-1.2-PCCDI2017-0833.

\section{References}

1 Tangjitgamol S, Manusirivithaya S, Sheanakul C, Leelahakorn $\mathrm{S}$, Thawaramara $\mathrm{T}$ and Jesadapatarakul S: Squamous cell carcinoma arising from dermoid cyst: Case reports and review of literature. Int J Gynecol Cancer 13(4): 558-563, 2003. PMID: 12911740. DOI: 10.1046/j.1525-1438.2003.13312.x

2 Dos SL, Mok E, Iasonos A, Park K, Soslow RA, Aghajanian C, Alektiar K, Barakat RR and Abu-Rustum NR: Squamous cell carcinoma arising in mature cystic teratoma of the ovary: a case series and review of the literature. Gynecol Oncol 105(2): 321324, 2007. PMID: 17240432. DOI: 10.1016/j.ygyno.2006.12.008

3 Peterson WF: Malignant degeneration of benign cystic teratomas of the overy; a collective review of the literature. Obstet Gynecol Surv 12(6): 793-830, 1957. PMID: 13493921. DOI: 10.1097/ 00006254-195712000-00001

4 Hackethal A, Brueggmann D, Bohlmann MK, Franke FE, Tinneberg HR and Munstedt K: Squamous-cell carcinoma in mature cystic teratoma of the ovary: systematic review and analysis of published data. Lancet Oncol 9(12): 1173-1180, 2008. PMID: 19038764. DOI: 10.1016/S1470-2045(08)70306-1

5 Caspi B, Lerner-Geva L, Dahan M, Chetrit A, Modan B, Hagay $\mathrm{Z}$ and Appelman $\mathrm{Z}$ : A possible genetic factor in the pathogenesis of ovarian dermoid cysts. Gynecol Obstet Invest 56(4): 203-206, 2003. PMID: 14614249. DOI: 10.1159/000074755

6 Avci S, Selcukbiricik F, Bilici A, Ozkan G, Ozagari AA and Borlu F: Squamous cell carcinoma arising in a mature cystic teratoma. Case Rep Obstet Gynecol 2012: 314535, 2012. PMID: 23320213. DOI: $10.1155 / 2012 / 314535$

7 Park SB, Kim JK, Kim KR and Cho KS: Imaging findings of complications and unusual manifestations of ovarian teratomas. Radiographics 28(4): 969-983, 2008. PMID: 18635624. DOI: $10.1148 / \mathrm{rg} .284075069$

8 Hirakawa T, Tsuneyoshi $\mathrm{M}$ and Enjoji $\mathrm{M}$ : Squamous cell carcinoma arising in mature cystic teratoma of the ovary. Clinicopathologic and topographic analysis. Am J Surg Pathol 13(5): 397-405, 1989. PMID: 2712191. DOI: 10.1097/00000478198905000-00007

9 Kashimura M, Shinohara M, Hirakawa T, Kamura $\mathrm{T}$ and Matsukuma K: Clinicopathologic study of squamous cell carcinoma of the ovary. Gynecol Oncol 34(1): 75-79, 1989. PMID: 2737532. DOI: 10.1016/0090-8258(89)90111-x

10 Kikkawa F, Nawa A, Tamakoshi K, Ishikawa H, Kuzuya K, Suganuma N, Hattori S, Furui K, Kawai M and Arii Y: Diagnosis of squamous cell carcinoma arising from mature cystic teratoma of the ovary. Cancer 82(11): 2249-2255, 1998. PMID: 9610706. DOI: $10.1002 /$ (sici) 1097-0142(19980601)82:11<2249::aidcncr21>3.0.co;2-t

11 Yamanaka Y, Tateiwa Y, Miyamoto H, Umemoto Y, Takeuchi Y, Katayama $\mathrm{K}$ and Hashimoto $\mathrm{K}$ : Preoperative diagnosis of malignant transformation in mature cystic teratoma of the ovary. Eur J Gynaecol Oncol 26(4): 391-392, 2005. PMID: 16122185.
12 Kido A, Togashi K, Konishi I, Kataoka ML, Koyama T, Ueda H, Fujii $\mathrm{S}$ and Konishi J: Dermoid cysts of the ovary with malignant transformation: MR appearance. AJR Am J Roentgenol 172(2): 445-449, 1999. PMID: 9930800. DOI: 10.2214/ajr.172.2.9930800

13 Miyazaki K, Tokunaga T, Katabuchi H, Ohba T, Tashiro H and Okamura H: Clinical usefulness of serum squamous cell carcinoma antigen for early detection of squamous cell carcinoma arising in mature cystic teratoma of the ovary. Obstet Gynecol 78(3 Pt 2): 562-566, 1991. PMID: 1870825.

14 Ulker V, Numanoglu C, Akbayir O, Akyol A, Tuncel A, Akca A and Aydin O: Malignant transformation arising from mature cystic teratoma of the ovary: a report of six cases. J Obstet Gynaecol Res 38(5): 849-853, 2012. PMID: 22448642. DOI: 10.1111/j.1447-0756.2011.01797.x

15 Wang PH, Yen MS, Juang CM, Chen YJ, Chao HT and Yuan CC: Intraperitoneal cancer spread after laparoscopic cystectomy for mature teratoma with malignant transformation. Eur J Gynaecol Oncol 23(2): 131-132, 2002. PMID: 12013109.

16 Mecke H and Savvas V: Laparoscopic surgery of dermoid cysts-intraoperative spillage and complications. Eur J Obstet Gynecol Reprod Biol 96(1): 80-84, 2001. PMID: 11311766. DOI: 10.1016/s0301-2115(00)00390-0

17 Gadducci A, Guerrieri ME and Cosio S: Squamous cell carcinoma arising from mature cystic teratoma of the ovary: A challenging question for gynecologic oncologists. Crit Rev Oncol Hematol 133: 92-98, 2019. PMID: 30661663. DOI: 10.1016/j.critrevonc.2018.10.005

18 Sinha A and Ewies AA: Ovarian mature cystic teratoma: Challenges of surgical management. Obstet Gynecol Int 2016: 2390178, 2016. PMID: 27110246. DOI: 10.1155/2016/ 2390178

19 Mayer C, Miller DM and Ehlen TG: Peritoneal implantation of squamous cell carcinoma following rupture of a dermoid cyst during laparoscopic removal. Gynecol Oncol 84(1): 180-183, 2002. PMID: 11748999. DOI: 10.1006/gyno.2001.6484

20 Pantoja E, Rodriguez-Ibanez I, Axtmayer RW, Noy MA and Pelegrina I: Complications of dermoid tumors of the ovary. Obstet Gynecol 45(1): 89-94, 1975. PMID: 1110824.

21 Rose PG, Tak WK and Reale FR: Squamous cell carcinoma arising in a mature cystic teratoma with metastasis to the paraaortic nodes. Gynecol Oncol 50(1): 131-133, 1993. PMID: 8349156. DOI: 10.1006/gyno.1993.1178

22 Tseng CJ, Chou HH, Huang KG, Chang TC, Liang CC, Lai CH, Soong YK, Hsueh S and Pao CC: Squamous cell carcinoma arising in mature cystic teratoma of the ovary. Gynecol Oncol 63: 64-70, 1996. PMID: 8946873. DOI: 10.1006/gyno.1996.0337

23 Chen RJ, Chen KY, Chang TC, Sheu BC, Chow SN and Huang SC: Prognosis and treatment of squamous cell carcinoma from a mature cystic teratoma of the ovary. J Formos Med Assoc 107(11): 857-868, 2008. PMID: 18971155. DOI: 10.1016/S09296646(08)60202-8

24 Glasspool RM, Gonzalez MA, Millan D, Lorusso D, AvallLundqvist E, Hurteau JA, Davis A, Hilpert F, Kim JW, Alexandre J and Ledermann JA: Gynecologic Cancer InterGroup (GCIG) consensus review for squamous cell carcinoma of the ovary. Int J Gynecol Cancer 24(9 Suppl 3): S26-S29, 2014. PMID: 25126954. DOI: 10.1097/IGC.0000000000000209

25 Bacalbasa N, Balescu I, Dima S, Herlea V, David L, Brasoveanu $\mathrm{V}$ and Popescu I: Initial incomplete surgery modifies prognosis 
in advanced ovarian cancer regardless of subsequent management. Anticancer Res 35(4): 2315-2320, 2015. PMID: 25862895

26 Bacalbasa N, Balescu I, Dima S, Brasoveanu V and Popescu I: Hematogenous splenic metastases as an independent negative prognosis factor at the moment of primary cytoreduction in advanced stage epithelial ovarian cancer - a single center experience. Anticancer Res 35(10): 5649-5654, 2015. PMID: 26408738.

27 Bacalbasa N, Balescu I, Dima S and Popescu I: Ovarian sarcoma carries a poorer prognosis than ovarian epithelial cancer throughout all FIGO stages: a single-center case-control matched study. Anticancer Res 34(12): 7303-7308, 2014. PMID: 25503164.

28 Bacalbasa N, Balescu I, Dima S, Brasoveanu V and Popescu I: Splenectomy as part of cytoreductive surgery in recurrent epithelial ovarian cancer. Anticancer Res 35(9): 5097-5101, 2015. PMID: 26254413.

29 Bacalbasa N, Balescu I, Dima S, Brasoveanu V and Popescu I: The role of quaternary cytoreduction in recurrent epithelial ovarian cancer: a single-center experience. Anticancer Res 35(6): 3519-3523, 2015. PMID: 26026119.

30 Abhilasha N, Bafna UD, Pallavi VR, Rathod PS and Krishnappa $\mathrm{S}$ : A review of squamous cell carcinoma arising in mature cystic teratoma of the ovary. Indian J Cancer 53(4): 612-614, 2016. PMID: 28485364. DOI: 10.4103/0019-509X.204763
31 Chen P, Yeh CC, Lee FK, Teng SW, Chang WH, Wang KC and Wang PH: Squamous cell carcinoma occurring in the pelvis after total hysterectomy and bilateral salpingo-oophorectomy for an ovarian mature teratoma with malignant transformation. Taiwan J Obstet Gynecol 51(3): 446-448, 2012. PMID: 23040935. DOI: 10.1016/j.tjog.2012.07.025

32 Park JY, Kim DY, Kim JH, Kim YM, Kim YT and Nam JH: Malignant transformation of mature cystic teratoma of the ovary: experience at a single institution. Eur J Obstet Gynecol Reprod Biol 141(2): 173-178, 2008. PMID: 18823690. DOI: 10.1016/ j.ejogrb.2008.07.032

33 Comerci JT Jr., Licciardi F, Bergh PA, Gregori C and Breen JL: Mature cystic teratoma: a clinicopathologic evaluation of 517 cases and review of the literature. Obstet Gynecol 84(1): 22-28, 1994. PMID: 8008317.

Received March 28, 2020

Revised April 2, 2020

Accepted April 3, 2020 